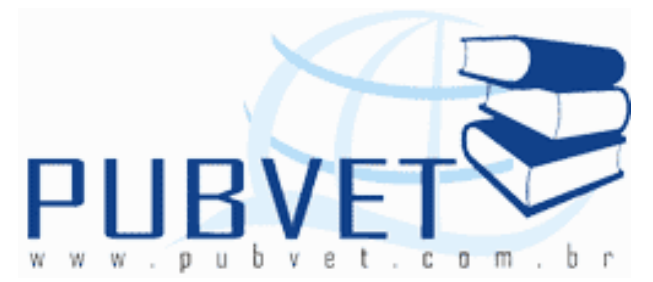

PUBVET, Publicações em Medicina Veterinária e Zootecnia.

\title{
Condrossarcoma na articulação femoro-tíbio-patelar de um cão: Relato de caso
}

Luiz Augusto de Souza ${ }^{1}$, Taís Andrade Dias ${ }^{2}$, Jalily Bady Helou ${ }^{3}$,

Bruno Sousa Dias ${ }^{4}$, Nadine Bou Fares ${ }^{5}$, Francisco Cláudio Dantas Mota ${ }^{6}$,

Elisa Machado de Almeida ${ }^{5}$, Laiz Alves Pereira ${ }^{5}$, Tamires de Paula e Silva ${ }^{5}$

${ }^{1}$ Médico Veterinário. Professor adjunto I da Universidade Federal de Goiás. Escola de Veterinária da UFG.E-mail: souza_vet@yahoo.com.br

${ }^{2}$ Médica Veterinária. Doutoranda em Ciência Animal. Universidade Federal de Goiás (UFG).

${ }^{3}$ Médica Veterinária. Universidade Federal de Goiás (UFG).

${ }^{4}$ Médico Veterinário.Universidade Federal de Goiás (UFG) Campus Jataí

${ }^{5}$ Graduanda em Medicina Veterinária. Universidade Federal de Goiás (UFG).

${ }^{6}$ Médico Veterinário. Professor adjunto I da Universidade Federal de Uberlândia. FAMEV/UFU

\section{Resumo}

Os condrossarcomas são neoplasias malignas, com prognóstico ruim a reservado, podem afetar diversasespécies domésticas, assim como o ser humano.São mais prevalentes em cães adultose de raças grandes, originandose, na maiorparte dos casos, em ossos chatos e esqueleto apendicular. O presente relato descreve os achados clínicos e radiográficos de um condrossarcoma na região da articulação femoro-tíbio-patelar de um cão da raça boxer e o tratamento preconizado. No exame clínico e físico,o animal 
SOUZA, L.A. et al. Condrossarcoma na articulação femoro-tíbio-patelar de um cão: relato de caso. PUBVET, Londrina, V. 8, N. 12, Ed. 261, Art. 1735, Junho, 2014.

apresentava claudicação do membro pélvico esquerdo, que durante a palpação foi observada a existência de uma fratura na porção distal do fêmur.O exame radiográfico revelouproliferação periosteal irregular, assim como a fratura já mencionada. O exame histológico foi realizado após serem colhidos fragmentos do côndilo lateral do fêmurque revelou condroblastos neoplásicos. Como tratamento, foi realizada a técnica de amputação meio femoral. No pósoperatório imediato foi realizada uma bandagem acolchoada com algodão ortopédico e ataduras. $O$ acompanhamento preventivo para o desenvolvimento de metástases foi recomendado por meio de exames radiográficos e ultrassonográficos.

Palavras-chave: Amputação, Condroblastos, Cirurgia oncológica.

\title{
Chondrosarcomaof the stifle joint in dog: Case report
}

\begin{abstract}
Chondrosarcomas are malignant neoplasias with reserved to poor prognosis which can affect several domestic species as well as humans. They are more prevalent in adult dogs and large breeds originating from flat bones and appendicular skeleton in the most cases. The present report describes the clinical and radiographic findings of chondrosarcoma in the stifle joint of a Boxer dog and recommended treatment. In clinical and physical examination the dog had left pelvic limb lameness which during palpation was observed the presence of a fracture in the distal femur. The radiographic exam revealed irregular periosteal proliferation as the aforementioned fracture. Histological examination was carried out after collected fragments from lateral condyle of the femur and revealed neoplasticschondroblasts. As treatment was performed the middle femoral amputation technique. In the immediate postoperative was made a padded bandage with orthopedic cotton and bandage. The preventive monitoring for development ofmetastasis was recommended by radiographic and ultrasonographic exams.
\end{abstract}

Keywords: Amputation, Chondroblasts, Cancer surgery. 
SOUZA, L.A. et al. Condrossarcoma na articulação femoro-tíbio-patelar de um cão: relato de caso. PUBVET, Londrina, V. 8, N. 12, Ed. 261, Art. 1735, Junho, 2014.

\section{INTRODUÇÃO:}

Além das fraturas traumáticas, existem as fraturas patológicas causadas por neoplasias ósseas como, por exemplo, osteossarcoma e condrossarcoma. Sabe-se que os ossos da região pélvica possuem baixa ocorrência de neoplasias malignas. Apesar disso, apresentam particularidades em seu tratamento em razão da complexidade anatômica da região e da dificuldade para sua ressecção com margem adequada (LOPES et al., 1997).

Dentre os três tipos de neoplasias que mais acometem a região pélvica esta o condrossarcoma (LOPES et al., 1997), que representa cerca de $10 \%$ do total das neoplasias ósseas diagnosticadas no cão (THOMPSON \&POOL, 2002). O condrossarcoma desenvolve-se no tecido cartilaginoso e é o segundo tumor primário mais comum, correspondendo a aproximadamente por $5 \%$ dos casos, com predileção pelas raças Pastor Alemão, Boxer (LIU, 1996) e Golden Retriever (KLEINER \& SILVA, 2003,). Em cães, esse tumor ocorre em idade média de 7,2 anos com faixa etária de seis a 14 anos (STRAW, 2004).

As regiões mais acometidas pelo condrossarcoma são a cavidade nasal que é o local mais comum em cães, costelas, ossos longos, pelve, vértebras, dígitos, osso peniano e nas regiões extra-esqueléticas, como glândula mamária, válvulas cardíacas, aorta, laringe, traqueia, pulmões e omento (STRAW, 2004). São tumores de crescimento lento e baixa incidência de metástase (KLEINER \& SILVA, 2003). Além disso, é uma neoplasia maligna na qual, células cartilaginosas tumorais produzem quantidades variáveis de matriz fibrilar neoplásica (COUTO, 2006) podendo se desenvolver primariamente em sítios esqueléticos (THOMPSON \&POOL, 2002; ROMANUCCI et al., 2005) ou raramente extra-esqueléticos (MILLER;WALSHAW; BOURQUE,2005; VOORWALD et al., 2008).

O tratamento dessa neoplasia é cirúrgico, com remoção do segmento acometido e amplas margens sadias (KAWAI \&FUKUSHIMA, 1998). Contudo, não raramente, pacientes que apresentam tumores infiltrados em grandes áreas, principalmente na pelve e nas estruturas adjacentes, não são tratados 
SOUZA, L.A. et al. Condrossarcoma na articulação femoro-tíbio-patelar de um cão: relato de caso. PUBVET, Londrina, V. 8, N. 12, Ed. 261, Art. 1735, Junho, 2014.

em razão da complexidade anatômica e da dificuldade deexcisão (ROMANO; FERREIRA; LOPES, 2004). Assim, o objetivo deste relato foi descrever um caso de fratura patológica de fêmur causada por condrossarcoma em um cão da raça Boxer com cinco anos de idade.

\section{RELATO DE CASO}

Foi realizado o atendimento no Hospital Veterinário da Universidade Federal de Goiás(HV\UFG) de uma cadela da espécie canina, raça Boxer, fêmea, com cinco anos de idade, pesando $27,8 \mathrm{~kg}$ e não castrada. A queixa principal da consulta relatada pelo proprietário foi que por volta de duas semanas o animal apresentou claudicação sem motivo aparente. Sem obter melhoras, dias depois a proprietárioprocurou um Médico Veterinário que diagnosticou pelo exame físico durante a palpação do membro posterior esquerdo a existência de uma fratura na porção distal do fêmur. Foi então prescrito pelo profissional o antiinflamatórioMeloxicam (Meloxil ${ }^{\circledR}$ ) $0,2 \mathrm{mg} / \mathrm{kg}$ e o analgésico Tramadol $\left(\right.$ Tramal $^{\circledR}$ ) na dose de $3,0 \mathrm{mg} / \mathrm{kg}$ ambos por via oral e solicitou o encaminhamento do animal para um especialista.

Durante 0 atendimento no HV\UFG, foi constatado que o animal apresentava hiporexia e normodipsia. As mucosas apresentavam-se normocoradas, estado de consciência alerta e sistema nervoso sem alteração, tempo de preenchimento capilar (TPC) menor que dois segundos, temperatura $38.9^{\circ}$ Celsius e linfonodos não reativos apalpação. A pele e os ouvidos apresentavam-se normais, frequências cardíaca e respiratória dentro da normalidade para a espécie. A urina e as fezes com aspecto, volume e frequência sem alterações aparentes. Além disso, não apresentava episódios de vômito e ou diarreia. A desverminação apresentava-se desatualizada, no entanto, as vacinas anti-rábica e a polivalente viral estavam em dia, porém sem o reforço anual. Não foi observada a presença de ectoparasitas como pulgas e/ou carrapatos. 
SOUZA, L.A. et al. Condrossarcoma na articulação femoro-tíbio-patelar de um cão: relato de caso. PUBVET, Londrina, V. 8, N. 12, Ed. 261, Art. 1735, Junho, 2014.

Mediante ao exame físico do aparelho locomotor e após a inspeção, constatou-se aumento de volume na região distal do fêmur esquerdo. À palpação, foi possível notar crepitação da articulação fêmoro-tíbio-patelar com manifestação de desconforto, caracterizando dor. Hipertermia local e sinal de Godet positivo em toda a região distal do membro pélvico esquerdo, inclusive nos dígitos também foi observado. Exames complementares como hemograma com pesquisa de hematozoários, bioquímicas séricas, dosagem de cálcio circulante foram solicitados juntamente com o exame radiográfico dos membros posteriores.

Após a realização do exame radiográfico foi observado na região da articulação fêmoro-tíbio-patelar esquerda uma fratura distal de fêmur de origem patológica (Figura 1). A alteração apresentava aspecto difuso que se estendia desde os côndilos do fêmur até o platô e a crista da tíbia, com fratura localizada nos côndilos femoral. Intensa reação periosteal irregular na porção distal, com áreas de esclerose e perda do tecido ósseo na região cortical, além de acentuado edema dos tecidos moles adjacentes foram observados.
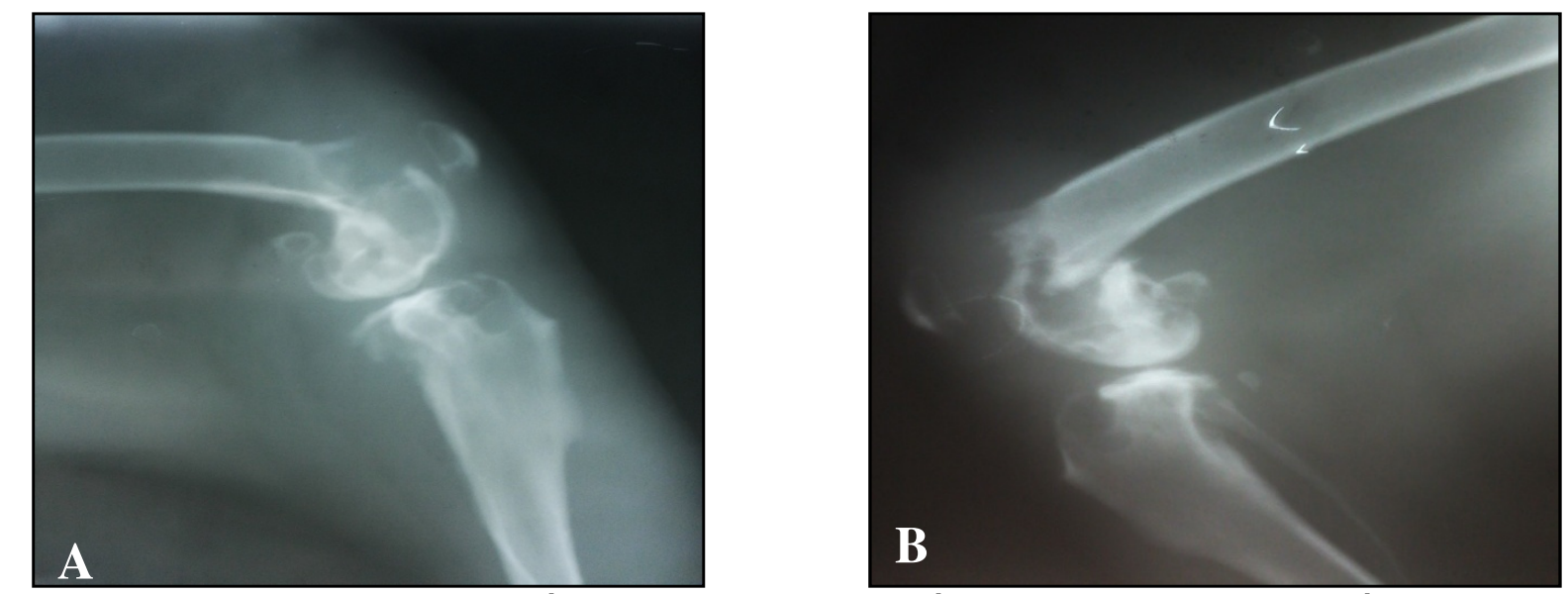

Figura 1: Imagem radiográfica em projeção látero-medial $(A)$ e médio-lateral (B) do fêmur de um cão da raça Boxer com cinco anos de idade. Observar fratura distal completa femoral esquerda com intensa reação periosteal de forma irregular na porção distal. Áreas de esclerose com perda do tecido ósseo da região cortical. 
SOUZA, L.A. et al. Condrossarcoma na articulação femoro-tíbio-patelar de um cão: relato de caso. PUBVET, Londrina, V. 8, N. 12, Ed. 261, Art. 1735, Junho, 2014.

Após a análise das imagens radiográficas, a suspeita de fratura distal do fêmur esquerdo foi confirmada, no entanto, com origem neoplásica. A partir dessas foi requerido o exame histopatológico para confirmar o diagnóstico. No dia seguinte, após a primeira consulta, o animal foi devidamente preparado para a realização da biópsia após tricotomia e antissepsia local. O acesso venoso foi feito com cateter no 22 e fluidoterapia com por solução de Ringer.

A biopsia foi realizada após o uso do protocolo pré-anestésico que incluía a associação de morfina $\left(\right.$ Dimorf $\left.^{\circledR}\right)$ 0,3mg/kg e Acepromazina (Acepran ${ }^{\circledR}$ ) na dose de $0,03 \mathrm{mg} \backslash \mathrm{kg}$, ambos por via intravenosa (IV). $\mathrm{Na}$ sequência, a indução anestésica foi realizada com Propofol (Diprivan ${ }^{\circledR}$ ) $5,0 \mathrm{mg} / \mathrm{kg}$ (IV) e o animal intubado por uma sonda orotraqueal que foi acoplada ao circuito anestésico. A manutenção durante todo o procedimento cirúrgico foi feita com anestésico inalatório Isoflurano (Forane ${ }^{\circledR}$ ).

Após o acesso cirúrgico pela região lateral da articulação do joelho esquerdo com abertura da cápsula articular, foram colhidos fragmentos do côndilo lateral do fêmur. A cápsula articular e os tecidos adjacentes foram reaproximados com sutura em padrão interrompido e fio inabsorvível n²-0. No pós-operatório, foram prescritos cloridrato de tramadol (Tramal ${ }^{\circledR}$ ) na dose de $2,0 \mathrm{mg} \backslash \mathrm{kg}$, antiinflamatórioMeloxicam $\left(\right.$ Movatec $^{\circledR}$ ) $0,2 \mathrm{mg} \backslash \mathrm{kg}$ e 0 antibiótico Cefalexina (Celesporin ${ }^{\circledR}$ ) $30 \mathrm{mg} / \mathrm{kg}$, todos por via oral. Dez fragmentos ósseos foram encaminhados para o exame histopatológico, sendo o menor com dimensões de $1,5 \times 0,7 \times 0,3 \mathrm{~cm}$ e o maior, $2,5 \times 2,0 \times 1,0 \mathrm{~cm}$,

Por meio do exame histopatológico e com base nos achados descritos no laudo, constatou-se extensa proliferação neoplásica de células mesenquimais. As células apresentavam citoplasma escasso, núcleo arredondado com cromatina frouxa e nucléolo proeminente em lacunas imersas em matriz cartilaginosa matura. Estas se caracterizam pela formação de tecido cartilaginoso maturo com discreta anisocariose e raras figuras de mitose, achados típicos de condrossarcoma.

Após a confirmação do condrossarcoma, a cirurgia de amputação meio femoral do membro pélvico esquerdo foi recomendada como melhor 
SOUZA, L.A. et al. Condrossarcoma na articulação femoro-tíbio-patelar de um cão: relato de caso. PUBVET, Londrina, V. 8, N. 12, Ed. 261, Art. 1735, Junho, 2014.

alternativa de tratamento para a neoplasia em questão. Antecedendo o procedimento cirúrgico, foram solicitados exames pré-operatórios, constatando que o animal estava apto para o procedimento cirúrgico recomendado. 0 animal foi encaminhado para a sala de preparação cirúrgica, onde foi obtido o acesso venoso e a fluidoterapia mantida com o Ringer simples. Em seguida, o animal recebeu protocolo pré-anestésico composto pelos mesmos fármacos utilizados na realização da biópsia, no entanto, também foi feito o uso do bloqueio loco-regional por via epidural com a lidocaína (Xilocaina ${ }^{\circledR}$ ) nadose de3,2mL, associada à bupivacaina (Bupivacaína ${ }^{\circledR}$ ) 2,5mL, morfina (Dimorf ${ }^{\circledR}$ ) $0,1 \mathrm{mg} / \mathrm{kg}$ efentanil2,0 $\mu \mathrm{g} / \mathrm{kg}$, que determinaram o bloqueio anestésico na altura máxima entre a quarta e quinta vértebras lombares.

Com o paciente em decúbito lateral direito foram realizadas a antissepsia e colocação dos campos cirúrgicos. Para a exérese da neoplasia com margens de tecidos saudáveis foi realizada uma incisão elíptica ao redor do membro posterior no nível do terço médio do fêmur (Figura 2A). Foi certificado que a face lateral da incisão na pele se estendeu mais distalmente do que a face medial. Ainda na face medial, o músculo grácil e o ventre caudal do músculo sartório foram transeccionados no nível meio-femoral. A artéria e veia femorais foram isoladas e ligadas com fio de ácido poliglicólico $n^{\circ} 0$ $\left(\right.$ Dexon ${ }^{\circledR}$ ) utilizando a técnica do pinçamento triplo.

Em seguida, o ventre cranial do músculo sartório foi transeccionado, assim como o bíceps femoral e o músculo quadríceps proximamente à patela. O nervo ciático foi isolado e seccionado no nível do terceiro trocanter, após receber um bloqueio anestésico com lidocaína (Xilocaina ${ }^{\circledR}$ ) (Figura 2B). Os músculos caudais, incluindo o semimembranoso, semitendinoso e adutor também foram seccionados no nível meio-femoral. A inserção do músculo adutor foi elevada e o fêmur serrado na porção entre os terços proximal e médio da diáfise femoral e assim, removendo o membro. 


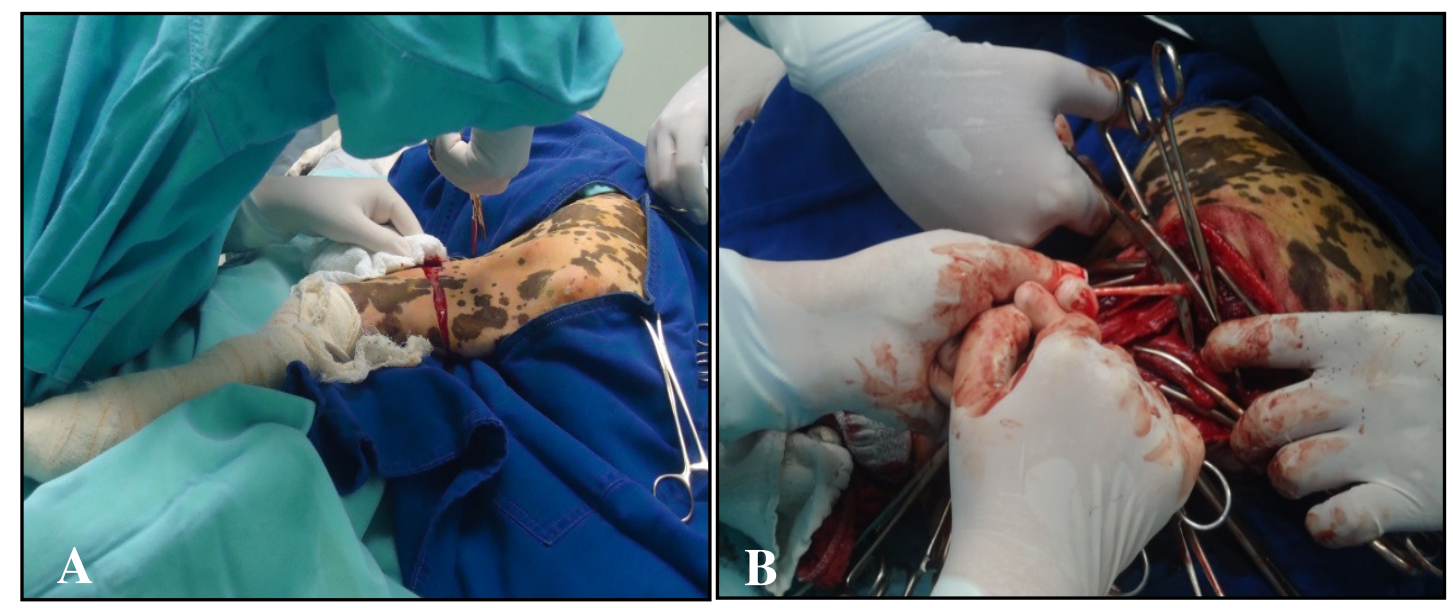

Figura 2: (A) Incisão elíptica ao redor do membro pélvico esquerdo com secção de músculos. (B) Tração no nervo ciático para secção após o bloqueioanestésico.

O ferimento cirúrgico foi fechado por um flape do músculo quadríceps para recobrir o coto femoral suturando-o no músculo adutor. O mesmo flape foi realizado no músculo bíceps femoral medialmente suturando-o aos músculos grácil e semitendinoso. A musculatura foi reaproximada com fio de ácido poliglicólico $n^{\circ} 0 \quad\left(D^{\infty} x n^{\circledR}\right)$ com pontos interrompidos para proteger a extremidade distal do fêmur. A redução do tecido subcutâneo foi realizada com sutura contínua simples e fio de ácido poliglicólico $n^{\circ} 2-0$ (Dexon ${ }^{\circledR}$ ) e a dermorrafia com sutura simples interrompida e fio Náilon n²-0 (Brasuture ${ }^{\circledR}$ ).

No pós-operatório imediato foi realizada uma bandagem acolchoada com algodão ortopédico e ataduras crepons que permaneceram por cinco dias, data do primeiro retorno para realização da troca de curativos e limpeza da ferida cirúrgica. Foram prescritos para o pós-cirúrgico, Dipirona Sódica (Dipidor $^{\circledR}$ ) na dose de 25,0mg/kg, Meloxicam (Maxican ${ }^{\circledR}$ ) 0,1 mg/kg e Tramadol (Dorless $V^{\circledR}$ ) 3,0mg/kg e antimicrobiano Cefalexina $\left(\right.$ Lexin $^{\circledR}$ ) 25,0mg/kg durante 10dias, todos por via oral. Após dez dias de pós-operatório, os pontos da pele foram removidos e foi dada alta médica ao paciente (Figura 3). 0 acompanhamento preventivo para o desenvolvimento de metástases foi recomendado por meio de exames radiográficos e ultrassonográficos. 


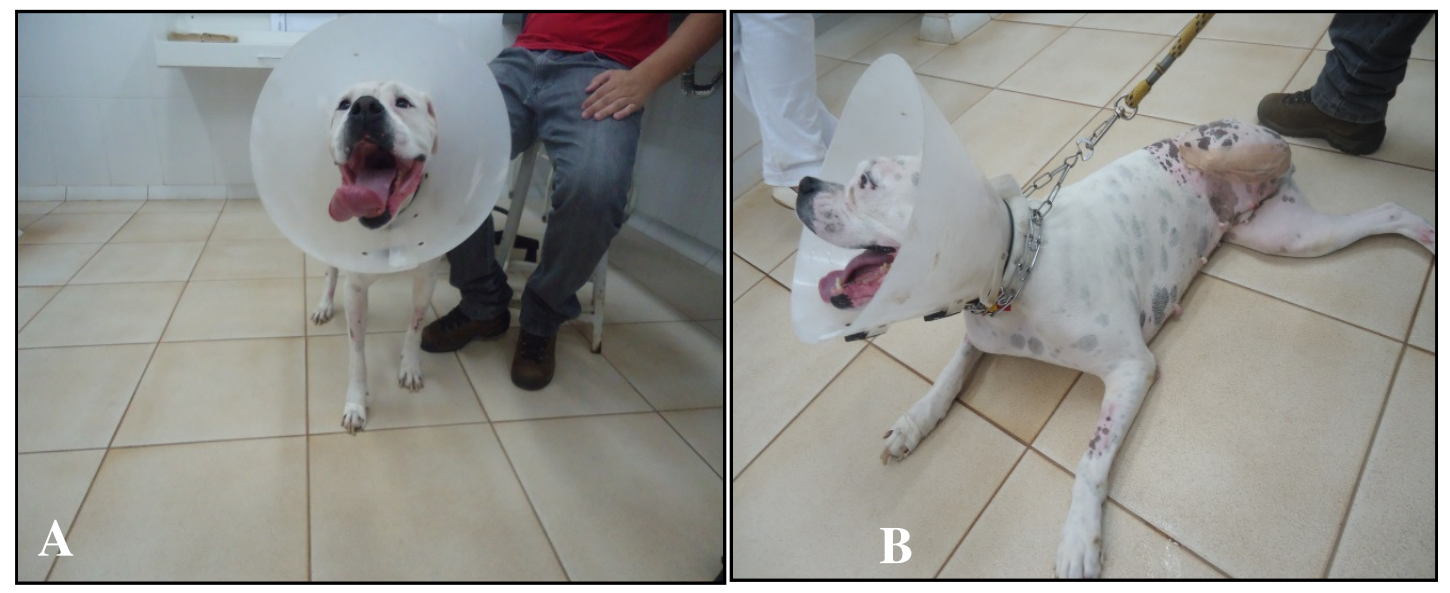

Figura 3: Animal de nome Julie, da raça boxer, com cinco anos, fêmea, utilizando o colar elizabetano (A), após amputação meio-femoral do membro esquerdo acometido por condrossarcoma (B).

\section{Discussão}

Tumores ósseos primários ou metastáticos são as causas mais comuns de fraturas patológicas (FOSSUM, 2002) e dentre estes os condrossarcomas estão relacionados. No cão, mais de $60 \%$ dos condrossarcomas têm sido identificados em ossos chatos, como costelas e pelve (POPOVITCH, 1994; BAILEY, 2007) locais que diferem do caso apresentado. Geralmente apresenta evolução clínica lenta (PENNA et al., 1996) e é proveniente de tecidos cartilaginosos (BURKEY et al., 1990), sendo que em cães e gatos é mais encontrado no esqueleto axial (OGILVIE, 2004).

É um tumor localmente invasivo, tendo grande propensão a recidivas (BURKEY et al., 1990), mas baixa incidência de formação de metástase (SHAW \&IHLE, 1999) o que corrobora com os achados do presente relato, uma vez que o paciente não apresentava sinais evidentes de metástase no tórax e nos tecidos moles adjacentes. Com relação aos sintomas, o paciente deste relato evitava apoiar o membro no solo e a dor à palpação era evidente na região alterada. PENNA et al. (1996) afirmaram que em seres humanos, os sintomas são bem semelhantes e incluem dor e aumento de volume local. A claudicação 
SOUZA, L.A. et al. Condrossarcoma na articulação femoro-tíbio-patelar de um cão: relato de caso. PUBVET, Londrina, V. 8, N. 12, Ed. 261, Art. 1735, Junho, 2014.

é um dos sinais característicos de animais acometidos por condrossarcomas (THOMPSON \&POOL, 2002) fato observado no presente relato, porém não conclusivo, pois afecções ortopédicas e neurológicas também podem promover claudicação, que pode variar de mínima até aquela que impede o apoio do membro, dados também questionados por BAILEY (2007).

Os condrossarcomas apresentam uma variada aparência radiológica, o que torna difícil sua distinção dos osteossarcomas (THOMPSON\& POOL, 2002). A lesão pode apresentar osteólise e reação periosteal, achados aqui descritos, e conter pontos de calcificação e ossificação intralesional, além do espessamento da cortical (KEALY\&MCALLISTER, 2005). A radiografia embora inespecífica apresentou informações valiosas, uma vez que, quanto mais radiotransparente o tumor maior a probabilidade de malignidade, conforme citaram GOMES (2006). Assim, optou-se por realizar o diagnóstico por meio do exame histopatológico, pois se deve realizar a diferenciação histológica de tumores mesenquimais envolvendo cartilagens, nos quais abrange o condrossarcoma, osteossarcoma e outros tipos de sarcomas (THOMPSON\&POOL, 2002).

O tratamento consistiu na ressecção cirúrgica do terço médio do fêmur esquerdo com amplas margens, pois segundo TERABE; ROSSI; LOPES (2005) a maioria dos casos não responde a outras modalidades de terapia. A amputação do membro pélvico pode ser realizada na diáfise média femoral, ou pela desarticulação da articulação coxofemoral. Quando os tumores acometem a articulação coxofemoral, a mesma deve ser desarticulada e todo o fêmur removido (FOSSUM, 2002). No presente relato, apenas a porção distal do fêmur esquerdo, assim como o platô tibial foram acometidos. Por opção e baseado na literatura consultada, optou-se pela ressecção na porção média da diáfise femoral, uma vez que a desarticulação coxofemoral trata-se de um procedimento invasivo e dispendioso para este caso.

O prognóstico para cães com condrossarcoma, tratados unicamente com ressecção óssea ou em combinação com quimioterapia é mais favorável quando comparado a neoplasias mais agressivas como o osteossarcoma. 
SOUZA, L.A. et al. Condrossarcoma na articulação femoro-tíbio-patelar de um cão: relato de caso. PUBVET, Londrina, V. 8, N. 12, Ed. 261, Art. 1735, Junho, 2014.

Entretanto, os condrossarcomas pouco diferenciados, embora não causem metástases com frequência são localmente infiltrativos, de crescimento rápido e o prognóstico tende a ser reservado (FARESE et al., 2009). Analisando a literatura relacionada à neoplasia do tipo condrossarcoma, foi possível perceber que não há um consenso relacionado ao melhor tratamento, porém a cirurgia de retirada da parte afetada é sempre indicada e na maioria dos casos é o único tratamento.

\section{CONCLUSÕES}

A amputação do membro ou do local afetado pelo condrossarcoma ainda é um dos métodos mais eficazes de tratamento, mas a precocidade de procurar recurso tão logo seja observado o problema, torna o prognóstico mais favorável. Embora muitas das abordagens estejam ainda sendo pesquisadas, o uso de terapia múltipla com radioterapia e quimioterapia, incorporados a tratamentos inovadores, pode oferecer melhor opção terapêutica, principalmente para animais com neoplasias ósseas cujo prognóstico é extremamente desfavorável.

\section{REFERÊNCIAS BIBLIOGRÁFICAS}

1. BAILEY, D. B.Chondrosarcoma. In: COTÉ, E.Clinical veterinary advisor: dogs and cats.1. ed.Saint Louis: Mosby Elsevier, 2007. p.202-204.

2. BERG, J. R.; EGGER, E. L.; KONDE, L.J. Evaluation of prognostic factors for growth following distal femoral physeal injuries in 17 dogs.VeterinarySurgery, Davis, v. 13, n. 3, p.172-180, 1984.

3. BERG, R. J.; STRAW, R. C. Cirurgia para os tumores ósseos primários com preservação do membro. In: BOJRAB, M. J. Mecanismos de moléstias na Cirurgia de Pequenos Animais. 2. ed.São Paulo: Editora Manole,1996.p.1086-1092.

4. BOIANI, R. M. Redução pelo método de Rush de fraturas Salter-Harris nofêmur de cães. 2007. $15 \mathrm{f}$. Trabalho monográfico de conclusão de curso de clínica cirúrgica de pequenos animais - Universidade Castelo Branco, São Paulo, 2007.

5. BOUDRIEAU, R.J. Management of Salter type-I and type-II distal femoral fractures in the dog and cat. California Veterinarian, v.4, p. 25-27, 1983. 
6. BURKEY B.B.; HOFFMAN H. T.; BARKER S. R.; THORTON A. F \& MC.CLATCHEY K. D. Chondrossarcoma of the head and neek.The Laryngoscope, Bethesda, v. 100, n. 12, 1990.

7. CARRILLO, J. M.; SOPENA, J. J.; RUBIO, M. Experimental study of the use of nylonband in the resolution of rabbit's oblique fracture. In: WSAVA CONGRESS, 27; FECAVA CONGRESS, 8; AVEPA CONGRESS, 37, Sevilha, Spain, 2002. Proceedings ... Sevilha, Spain, 2002. 259 p.

8. COUTO, C.G. Distúrbios da cavidade nasal. In: NELSON. R.N.; COUTO, C.G. Medicina interna de pequenos animais.3. ed.Rio de Janeiro: Elsevier, 2006, Cap.15, p.181-182.

9. DALLABRIDA, A. L. Osteossíntese femural em cães através de transfixação esquelética interna: proposição de técnica. 2004. 53f. Dissertação de Mestrado, Universidade Federal de Santa Maria, 2004.

10. DALLABRIDA, A. L; SCHOSSELER, J. E; VENTURA de AGUIAR, E. S; AMENDOLA, G. F; SILVA J. H. S; SOARES, J. M.D.Análise biomecânica ex vivo de dois métodos de osteossíntese de fratura diafisária transversal em fêmur de cães.Rev. Ciência Rural, Santa Maria, v. 35, n.1. p.116-120, 2005.

11. DENNY, H.R. A guidetocanineandfelineorthopaedicsurgery.3 ed. Oxford: BlackwellScientificPublications, 1993,402f.

12. DENNY, H. R; BUTTERWORTH, S. J. Cirurgia Ortopédica em Cães e Gatos.4 ed. Roca: São Paulo, 2006, 504f.

13. FARESE J.P.; KIRPENSTEIJN J.; KIK M.; BACON N.J.; WALTMAN S.S.; SEGUIN B.; KENT M.; LIPTAK J.; ROD S.; CHANG M.N.; JIANG Y. \& WITHROW S.J. Biologic behavior and clinical outcome of 25 dogs with canine appendicular chondrosarcoma treated by amputation: A veterinary society of surgical oncology retrospective study. VeterinarySurgery, Davis, vol. 38, n. 8, p.914-919, 2009.

14. FOSSUM, T. W. Fundamentos da cirurgia ortopédica e tratamento de fraturas. In: Cirurgia de pequenos animais. São Paulo: Roca, 2002, Cap. 28, p.792-797, 905, 958-961.

15. FRANCZUSZKI, D.; CHALMAN, J.A.; BUTLER, H.C. The use of paired pins in the fixation of distal femur fractures in the dog and cat.Journalof American Animal Hospital Association, v. 22 , p. $173-178,1986$.

16. GIORDANO, P. P.; PADILHA FILHO, J. G.; LOLLI JR, J.Haste intramedular bloqueada modificada aplicada ao fêmur: Estudo clínico e experimental em cães.ARS VETERINARIA, Jaboticabal, v.22, n.3, p.184-191, 2006.

17. GOMES, A. C. N. Condrossarcoma em paciente com osteocondromatose múltipla: relato de caso e revisão da literatura. Radiologia Brasileira, São Paulo, v.39, n.6, p.449-451, 2006.

18. KALFAS, I. H. Principlesofbonehealing. Neurosurgery Focus, v.10, p.1-4, abr. 2001.

19. KAWAI, A.; FUKUSHIMA, M. Prognostic factors for patients with sarcomas of the pelvic bones. American Cancer Society, Baltimore, v.82, n.5, p.851-859, 1998.

20. KEALY, J.K.; MCALLISTER, H. Ossos e articulações. In: Radiologia e ultra-sonografia do cão e do gato. 3.ed. Barueri: Manole, 2005, Cap.5, p.339-411. 
21. KLEINER, J. A; SILVA, E.G.Tumores ósseos em pequenos animais. Rev. Medvep, v.1, p.21-33, 2003.

22. LIU, S. Tumores ósseos e cartilaginósos. In: BOJRAB, M. J. Mecanismo de Moléstia na Cirurgia dos Pequenos Animais. 2a edição. São Paulo: Manole, 1996.

23. LOPES, A.; TERABE, F.; ROSSI B. M. Chondrosarcoma secondary to hereditary multipleex ostosis treated by extended internal hemiplevectomy. São Paulo Medical Journal, v.115, n.3, p.1440-1443, 1997.

24. LUCAS, S. S; ALIEVI, M. M; CONY, A. V; SCHOSSLER, J. E. W.Fraturas distais de fêmur em cães e gatos: Revisão de 55 casos.Revista da FZVA Uruguaiana, v.7/8, n.1, p. 75-83, 2000/2001.

25. MILLER, J. M.; WALSHAW, R.; BOURQUE, A. C. Primary splenic mesenchymal chondrosarcoma in a dog. Canadian Veterinary Journal, v.46, p.163-165, 2005.

26. MILTON, J. L.; HORNE, R.D.; GOLDSTEIN, G.M. Cross Pinning: A simple technique for treatment of certain metaphyseal and physeal fractures of the long bones. Journal of Americam Animal Hospital Association, v.16, p.891-905, 1980.

27. OGILVIE, G. K. TumoresósseosIn: ROSENTHAL R.C. (Ed).Segredos em Oncologia Veterinária. Porto Alegre: ARTMED, 2004, p.183-191.

28. PARKER, R.B.; BLOOMBERG, M.S. Modified intramedullary pin technique for repair of distal femoral physeal fractures in the dog and cat. JournalofAmericamVeterinarian Medical Association, v. 184, n.10, p.1259-1265, 1984.

29. PENNA V.; CHUNG, W. T.; LOPES, A.; TANAKA, M. H. Condrossarcoma: experiência do Hospital A.C. Camargo nos últimos 42 anos. Revista Brasileira de Ortopedia, São Paulo, v.31, n.11, p.888-890, 1996.

30. PIERMATTEI D.L. \& FLO G.L. Condições patológicas em animais de pequeno porte. In:Manual de Fraturas dos Pequenos Animais.3.ed. São Paulo: Manole, 1999, p.675-676.

31. POPOVITCH, C.A. Chondrosarcoma: A retrospective study of 97 dogs (19871990). Journal of American Animal Hospital Association, Lakewood, v.30, p.81-85, 1994.

32. REMEDIOS, A. Bone and bone healing. Veterinary Clinics of North America: Small Animal Practice, v.29, n.5, p. 1029-1044, set.1999.

33. ROMANO, M.;FERREIRA, F.O. ; LOPES, A.Hemipelvectomia interna alargada no tratamento de condrossarcoma pélvico localmente avançado: relato de caso. Revista Brasileira de Ortopedia, São Paulo, v.39, n.3, p.132-136, 2004

34. ROMANUCCI, M.; BONGIOVANNI, L.; PETRIAZZI, L.; SALDA, L. D. Cutaneousextraskeletalmesenchymalchondrosarcoma in a cat.Veterinary Dermatology, v.16, p.121-124, 2005.

35.SCHRADER, S. C.Complications associated with the use of Steinmann intramedullary pins and cerclage wires for fixation of long-bone fractures.Veterinary Clinical of North American Small Animal Practice, v.21, n. 4, p.687- 703, 1991.

36. SHAW, D.; IHLE, S.Doenças oncológicas In: Medicina Interna de Pequenos Animais. Porto Alegre: ARTMED, 1999, p.630-643. 
37. STRAW, R. C. Tumores Ósseos e Articulares. In: ETTINGER, S. J. Tratado de Medicina Interna Veterinária - Doenças do Cão e do Gato. 5a edição.Rio de Janeiro; Editora Guanabara Koogan, 2004.

38. SUMNER-SMITH, G., DINGWAll, J. S. A technique for repair of fractures of the distal femoral epiphysis in the dog and cat.JournalofAmericam Animal Hospital Association, v.9, p.171-174, 1973.

39.TERABE, F.;ROSSI B. M.; LOPES A. Condrossarcoma de ramo púbico superior simulando hérnia inguinal. Revista do Colégio Brasileiro de Cirurgia, Rio de Janeiro, v.32, n.6, p.353344, 2005.

40. THOMPSON, K. G.; POOL, R.R. Tumors of bones. In: MEUTEN D.J. (Ed). Tumors in Domestic Animals. 4th ed. Iowa: Iowa State Press, 2002, p.245-317.

41. TUDURY, E.A.; RAISER, A.G. Redução de fraturas distais do fêmur de cães, empregando dois pinos de Steinmann em substituição aos de Rush.Revista do Centro de Ciências Rurais, v.15, n.2, p.141-155, 1985. 